\title{
Performance and Home Advantage in Handball
}

\author{
by \\ Miguel Pic ${ }^{1}$
}

The main objective of this research was to delve into the concept of playing handball at home from a classical perspective of previous studies. The emergence of regularities or certain patterns of play can be explained by the location of matches. Through an observational methodology and a nomothetic, monitoring and multidimensional design, thirtynine European elite handball matches were selected $(N=39)$. A mixed 'ad hoc' registration system was designed. Records were made of the last three minutes of home and visiting games of which images were available. Two observers with observational methodology experience participated in the study. The quality of the records was dealt with in an intraobserver and interobserver way. Two different techniques were applied for the treatment of the data: a) detection of behavioral patterns by Theme ( $p$.005) (Magnusson, 2000) and $b$ ) Chaid decision trees $(p<.05)$ using SPSSv.24. The results showed the existence of T-patterns according to the location (different T-patterns: home: 1085; away: 1242) of the matches. The categories most involved in effective launches were unveiled. On the other hand, the Chaid model also showed the effect of location ( $p .001)$ : home-win (node 9) $(n=149,69 \%)$, away-win (node 10) $(n=15,16 \%)$ in handball. Crossing analysis offered enriched interpretations to advance in the home advantage concept. From this study, guidelines can be drawn that may help handball coaches to build training tasks as differences in behavioral patterns between home or away play in handball were identified. Thus, designing tasks considering a match location has requires specificity.

Key words: handball, home advantage, theme, game observational.

\section{Introduction}

Handball is an invasive cooperationopposition sport. Scoring more goals than the opposing team guides the strategic facet as a primary aim. Among the factors that affect performance of handball teams (Lago-Peñas et al., 2016), the advantage of playing at home (HA) seems to have been consistent (Pollard, 1986; Courneya and Carron, 1992) in different sport disciplines. In general, in team sports the HA was around $60 \%$ (Jamieson, 2010). The HA has also been investigated in martial arts (Krumer, 2017), questioned in tennis (Koning, 2011); moreover, gender related differences with regard to the HA have been found in judo (Julio et al., 2013). There seems to be consensus that the HA phenomenon is multifactorial (Pollard, 2008; Pollard and Pollard, 2005). It should not be forgotten that some authors have observed a HA reverse effect in such sports as hockey (Wright and Voger, 1995) or golf (Wright and Jackson, 1991).

It was confirmed that sports practiced in closed spaces, especially basketball and handball, reached higher HA values than other sports (Pollard et al., 2017). In handball, the HA in the main league in Germany was estimated at the level of $66 \%$ (Strauß and Bierschwale, 2008), while in the Spanish league values of $61 \%$ were found (Gómez et al., 2011; Gutiérrez et al., 2012) and 67\% in male teams (Gutiérrez et al., 2015).

The strategic guidelines transmitted by coaches to their players can be crucial for the study of motor behavior of players when competing (Staufenbiel et al., 2015). The use of an observational methodology (Anguera, 1979) to investigate the phenomenon of the HA in soccer

1 - University of La Laguna, Department of Specific Didactics. La Laguna, Tenerife (Spain). 
attack actions has been novel (Diana et al., 2017). In this study, it was revealed that the strategic structure identified using Theme (Magnusson, 2000) was poorer when playing as a visiting team than as a home one. Thus, home teams braided more structured itineraries than their rival teams. The application of this technique in different sports (Borrie et al., 2002) has revealed sequences of events that are difficult to appreciate through other analytical techniques. In initiation soccer, it was also observed that children presented different problems of adaptation at the age of 7 and 8 (Amatria et al., 2017). Following an observational methodology in handball, strategically, the most used systems have been the structured ones (Lozano and Camerino, 2012); furthermore, success of the team seems to depend on the participation of left \& right wingers (Montoya et al., 2013).

From all of the above, the existence of the HA can be inferred from a quantitative approach, although some authors have questioned such effects (Wright and Voger, 1995). Considering the scarcity of studies that address situational variables, the main objective of this study was to determine the existence of the HA at the elite level in handball. We hypothesized that the HA would occur in the last minutes of handball matches played at the elite level.

\section{Methods}

One of the benefits offered by the use of an observational methodology (Anguera, 2017) is its adaptation to different practice contexts. In this sense, it also allows greater flexibility based on the selection and definition of criteria for the development of rigorous systems of 'ad hoc' registration.

Design

Quadrant III (Anguera et al., 2011) was the base for the design of the study. The present study was nomothetic, because different players were observed; punctual, due to the fact that the teams were not followed in their participation in the respective championships. On the other hand, the study is multidimensional due to the use of several criteria for the elaboration of the mixed registration system.

Selection of Matches

We used an intentional sample (Amatria et al., 2016). The chosen matches met three inclusion criteria: a) sufficient video quality; b) three or less goals in favor of the winning team in the final score; c) played during one of the last three seasons (2015-16, 2016-17 or 2017-18). A search of handball matches played within three of the best European leagues was made and finally 39 matches were selected for further analysis: 14 matches of the Asobal League, 14 matches of the German Bundesliga and 11 matches of the French league, known as Lidl Starligue. Of these matches, 17 ended with a victory for the home teams, 17 with a victory for the visitor teams, while 5 matches ended in a draw.

\section{Registration System}

The registration system is a fusion between a category system and a field format. In this way, it was possible to take advantage of the rigor of the category system and the flexibility or adaptability of the field format. Each of the 7 criteria of the system gives rise to one of the 36 categories. This registration system fulfilled the conditions of completeness and mutual exclusivity (E / ME). That is, the definition of each category was unique and, therefore, the selection of one category made it impossible for another to be activated, at least simultaneously.

The registration system was composed of 7 criteria and 36 categories. Some of the criteria and / or categories are briefly described below for better understanding. The first criterion 'location' referred to whether the team played as a home $(\mathrm{H})$ or a visitor $(\mathrm{Y})$ team. The second criterion 'final result' reflected the result at the end of the match that could be either victory (W), defeat (L) or tie (D). The 'scoreboard evolution' criterion was the largest one and included 13 categories. Through this criterion the evolution of the scoreboard was assessed, from 0 goals of difference between the teams (ti) to \pm 6 goals. The positive sign took the home team as a reference, that is; when the home team won by one goal then it was considered $+1(\mathrm{o})$, whereas when the home team lost by one goal, then -1 (ol) was obtained.

The fourth criterion referred to the special distribution of the teams. Thus, we focused on the actions that the teams made when crossing the midfield line. The playing field was divided longitudinally into two sectors: left and right. We considered the actions when players crossed the midfield line, before crossing the $9 \mathrm{~m}$ line on the left (l) or right (r), and between the goal area and 
the $9 \mathrm{~m}$ on the left (lt) and on the right (ri). The fifth criterion 'attack' was developed considering the actions resulting in lost ball possession (lb) understanding these as the actions in which the ball was lost because of an error made by the team possessing the ball rather than an intervention of the opponent.

\section{Procedures}

First all the selected handball matches were downloaded from the YouTube portal. Two independent evaluators analysed the obtained records at two different times. To check their quality, inter and intra-observer reliability was assessed. Pearson and Spearman correlation coefficients were calculated, showing values close to one and never below 0.8 .

For the analysis of records, the Lince program was used (Gabín et al., 2012). The ball was focally monitored. Registration was never stopped, however, given that there were dead times or unexpected interruptions during matches, a 'Time Obs' criterion was used with regard to moments in which the ball was not in motion. The last three minutes of each match were recorded. Sometimes, at that precise period, an incomplete situation occurred. In these cases, a few seconds were allowed to pass before starting the registration. The completion of the registration of each match coincided with the end of the match indicated by the referee. Once all the records were completed, the Lince program was used again for the transformation of the data to excel and .txt.

\section{Data Analysis}

Through statistical software Theme v6 (Magnusson, 2000), the temporal perspective of the registers was addressed. This software has been developed to discover and analyze hidden repeated temporal and often multimodal patterns in behaviour. According to Magnuson (2000) 'if A is an earlier and $\mathrm{B}$ a later component of the same recurring T-pattern, then, after an occurrence of $\mathrm{A}$ at $\mathrm{t}$, there is an interval $[\mathrm{t}+\mathrm{d} 1, \mathrm{t}+\mathrm{d} 2](\mathrm{d} 2 \geq \mathrm{d} 1 \geq \mathrm{d} 0)$ that tends to contain at least one occurrence of $\mathrm{B}$ more often than would be expected by chance'.

Temporal regularities were detected using 3 events and levels of significance $(p<.005)$ in two moments for home and visiting teams. First, Tpatterns in teams were found, and then a search of specific regularities was made. In particular, the T-patterns were noted with regard to the following situations: scoring a goal (tg), ineffective throws (tf), reaching a draw (ti), advantage of a goal in favor of the home team (o) or disadvantage of a goal by the home team (ol).

Secondly, the statistical program SPSS v24 was used to apply multivariate analyses using decision trees (CHAID model). This timeless and complementary perspective of the analyses started from levels of significance $(p<.05)$ and cross validation. The dependent variable was the final result of the game, while the variables introduced as predictors of the model were: location, scoreboard evolution, zone, attack and defending.

\section{Results}

After conducting a search of T-patterns in home and visiting teams, the data reported that the number of T-patterns $(p<.005)$ differed depending on the location of the matches. On the one hand, it was found that by means of 4319 events, 1085 different T-patterns were constructed, coming from home teams. In contrast, 4513 events were required to add 1242 original T-patterns.

Table 3 shows some differences between home and visiting teams in relation to the original T-patterns and the number of events involved. First, the number of occurrences (events) needed to achieve goals was higher in home teams ( $\mathrm{n}=$ $826)$ versus visiting teams $(n=291)$. Similarly, the number of different T-patterns was greater in home teams $(n=267)$ than in visiting ones $(n=97)$. On the other hand, T-patterns were not found when the missed shots by both visiting and home teams were included in the search.

However, the teams with one goal more (o) than the opponent with the most number of occurrences $(n=1767)$ or T-patterns $(n=520)$ were the visiting ones, and not the home teams with the lowest number of occurrences $(\mathrm{n}=586)$ or $\mathrm{T}$ patterns $(n=191)$. Likewise, when the home teams had one goal (ol) below in the score, no occurrences or T-patterns were found, while the visitors obtained $(\mathrm{n}=747)$ occurrences and $(\mathrm{n}=$ 249) T-patterns. On the other hand, when the scoreboard indicated a draw (ti), the home teams obtained a greater number of occurrences $(\mathrm{n}=$ $2638)$ and T-patterns $(n=766)$ than visitors with a lower number of occurrences $(n=225)$ or $T$ patterns $(n=75)$.

The categories that made reference to the 
circulation in the space closest to the penalty area in the left (lt) and right (ri) sector obtained similar results between home and visiting teams. However, these results were more favorable to home teams, and slightly higher on the left side, as the number of occurrences was double in home teams $(\mathrm{n}=302)$ compared to visiting teams $(\mathrm{n}=$ 162).

The dendogram (Figure 2a) of the image describes one of the most complex T-patterns found in home teams. Teams with a momentary draw socre (ti) and winners at the end of the match (w) accumulated more than half of the occurrences or behaviors. On the other hand, the space usually used by home teams fluctuated between space (l) and (r). When analyzing the set of occurrences ( $w, t i, p, t g)$, which consisted of being the winning team at the end of the match, while with a momentary result of a draw, that throws a penalty and gets a goal, a change occurred. From that moment, home teams began to make passes in spaces far from the area in the left $(\mathrm{w}, \mathrm{o}, \mathrm{l})$ and right $(\mathrm{w}, \mathrm{o}, \mathrm{r})$ with a goal of advantage over the visiting team.

In the following image (Figure $2 b$ ) a more exhaustive search was carried out, including scoring a goal (tg). The dendogram that was generated indicated which were the itineraries followed by home teams to get the goal and the following consequences. There was a change of trends, as previously explained (Figure 2a). Figures $2 \mathrm{a}$ and $2 \mathrm{~b}$ are similar despite having modified the search variables. Figure $2 b$ also considered a goal (tg)a scored through a vertical line.

In Figure 2c, it was possible to verify that one of the temporary regularities attributed to visiting teams was to finish the matches losing (l), but also winning $(w)$. Following the second column of the occurrences you can verify that the teams were tied. The first set of behaviors (l, ti, it, gf) meant that the visiting team drew a foul committed by the opponent. After that, the use of a space in the left (l) and right ( $r$ ) sector was alternated until the team had a goal below in the scoreboard (ol). After a series of occurrences, the team went from losing (l) to being the winner $(\mathrm{w})$ and also with two goals of advantage over the home team $(w, t, l)$.

As with the home teams, a goal search (tg) was made in Figure 2d. Thus, the set of behaviors (l, ol, ri, tg) was decisive. After half-time (no), the visiting teams began to win $(\mathrm{w})$ the matches by one goal (or) or two (t) of difference with respect to the home teams.

In Figure 3, between nodes 1 and 6 it can be verified that the variable scoreboard $(p<.001)$ allowed for a segmentation of the records without continuity in most cases given that, except for nodes 3 and 5 , the rest were terminal nodes. In node 1 , home teams and visitors who had one (0) or three goals (th) of advantage over the opponent mostly offered occurrences of teams that finally won ( $\mathrm{n}=324,80 \%)$ the match against teams who lost $(n=41,10 \%)$ or tied $(n=38,9 \%)$. Continuing with node 1 , it can be highlighted that between the two markers, they formed the node with the highest number of occurrences ( $n=403,26 \%$ ). In contrast, node 6 , with four goals (fl) and five goals (fil) less than the rival team, was the one with the lowest frequencies ( $n=57,4 \%$ ).

Other nodes also obtained high percentages of occurrences as it can be seen in node 3 or node 4, but more than one marker was linked, while in node $2(\mathrm{n}=193,12 \%)$ most of the occurrences belonged to teams that lost $(n=161,83 \%)$. From node 3 with superior results over the rival, two branches were established $(p<.002$, Chi square 12.082 , df 2) that gave rise to home team nodes 7 $(\mathrm{n}=97,6 \%)$ and node 8 of visiting teams $(\mathrm{n}=138$, $9 \%$. More specifically, in node 7 most of the occurrences belonged to home teams that won (n $=84,87 \%$ ), while in node 8 the supremacy in terms of occurrences belonged equally to winning visiting teams $(\mathrm{n}=134,97 \%)$. Statistical support was evidenced by the branch found in node 5 ( $p<$ .001 , Chi square 116.844, df 2), because it responded to the tie score (ti), exclusively. The nodes born from this node evidenced differences in the number of occurrences between participating as home team in node $9(\mathrm{n}=217$, $14 \%)$ versus the visitor team in node $10(\mathrm{n}=93$, $6 \%$ ). When analyzing node 9 , it can be seen that with a tie marker, most of the occurrences were made by winning teams $(\mathrm{n}=149,69 \%)$ against teams that tied $(n=67,26 \%)$ or lost $(n=11,5 \%)$. The biggest changes that were found when comparing the previous node and the node 10, were evident not in the tying teams that obtained similar scores, but in contrast, in the visiting teams that won $(n=15,16 \%)$ and lost $(n=52,56 \%)$ (node 10). 
Table 1

Description of the handball matches analyzed in the study, both before and after their ending

\begin{tabular}{|c|c|c|c|c|c|c|c|c|}
\hline Championship & Match & Day & Sesion & Goal1 & Res1 & Goal2 & Res2 & Diff \\
\hline Liga Asobal & Teucro-Ademar & 8 & $2015-16$ & $25-27$ & $\mathrm{~V}$ & $28-27$ & $\mathrm{~L}$ & 3 \\
\hline Liga Asobal & Barcelona-Huesca & 30 & $2016-17$ & $29-28$ & $\mathrm{~L}$ & $30-29$ & $\mathrm{~L}$ & 0 \\
\hline Liga Asobal & La Rioja - Barcelona & 3 & $2016-17$ & $22-24$ & $\mathrm{~V}$ & $22-24$ & V & 0 \\
\hline Liga Asobal & Benidorm-Barcelona & 5 & 2016-17 & $25-27$ & $\mathrm{~V}$ & $27-30$ & $\mathrm{~V}$ & -1 \\
\hline Liga Asobal & Barcelona-Ademar & 10 & 2016-17 & $25-24$ & $\mathrm{~L}$ & $26-25$ & $\mathrm{~L}$ & 0 \\
\hline Liga Asobal & Villa Aranda-P. Sagunto & 17 & 2016-17 & $22-23$ & $\mathrm{~V}$ & $24-24$ & $\mathrm{D}$ & 1 \\
\hline Liga Asobal & $\begin{array}{l}\text { Ciudad Encantada-La } \\
\text { Rioja }\end{array}$ & 20 & 2016-17 & $28-27$ & L & $28-28$ & $\mathrm{D}$ & -1 \\
\hline Liga Asobal & Ademar-Barcelona & 25 & 2016-17 & $26-27$ & $\mathrm{~V}$ & $27-28$ & $\mathrm{~V}$ & 0 \\
\hline Liga Asobal & Bidasoa-Aranda & 16 & 2016-17 & $23-23$ & $\mathrm{D}$ & $24-23$ & $\mathrm{~L}$ & 1 \\
\hline Liga Asobal & Zamora-Teucro & 1 & $2017-18$ & $28-25$ & $\mathrm{~L}$ & $28-28$ & $\mathrm{D}$ & -3 \\
\hline Liga Asobal & Anaitasuna-Granollers & 2 & $2017-18$ & $26-25$ & $\mathrm{~L}$ & $28-27$ & $\mathrm{~L}$ & 0 \\
\hline Liga Asobal & P. Sagunto-Anaitasuna & 4 & $2017-18$ & $19-20$ & $\mathrm{~V}$ & $20-23$ & $\mathrm{~V}$ & -2 \\
\hline Liga Asobal & Teucro-Granollers & 4 & $2017-18$ & $25-26$ & $\mathrm{~V}$ & $26-27$ & $\mathrm{~V}$ & 0 \\
\hline Liga Asobal & Bidasoa Irún- La Rioja & 5 & 2017-18 & $25-25$ & $\mathrm{D}$ & $27-25$ & $\mathrm{~L}$ & 2 \\
\hline Lidl S.League & Montpellier-PSG & 8 & $2015-16$ & $30-29$ & $\mathrm{~L}$ & $32-31$ & $\mathrm{~L}$ & 0 \\
\hline Lidl S.League & Toulouse-A. Provence & 21 & $2015-16$ & $26-26$ & $\mathrm{D}$ & $28-27$ & $\mathrm{~L}$ & 1 \\
\hline Lidl S.League & Montpellier-Nantes & 12 & 2016-17 & $23-24$ & $\mathrm{~V}$ & $25-26$ & $\mathrm{~V}$ & 0 \\
\hline Lidl S.League & Aix-S. Rafael & 15 & $2016-17$ & $26-28$ & $\mathrm{~V}$ & $29-29$ & $\mathrm{D}$ & 2 \\
\hline Lidl S.League & Creteil-Nantes & 17 & $2015-16$ & $25-24$ & L & $25-26$ & $\mathrm{~V}$ & -2 \\
\hline Lidl S.League & Chamberri-Tolousse & 17 & 2016-17 & $29-27$ & $\mathrm{~L}$ & $30-29$ & $\mathrm{~L}$ & -1 \\
\hline Lidl S.League & Creteil-Dunkerke & 20 & 2016-17 & $29-31$ & $\mathrm{~V}$ & $31-34$ & $\mathrm{~V}$ & -1 \\
\hline Lidl S.League & Montpellier-PSG & 21 & $2016-17$ & $31-34$ & $\mathrm{~V}$ & $33-34$ & $\mathrm{~V}$ & 2 \\
\hline Lidl S.League & Nantes-Montpellier & 24 & 2016-17 & $28-32$ & $\mathrm{~V}$ & $30-33$ & $\mathrm{~V}$ & 1 \\
\hline Lidl S.League & PSG-Saran & 24 & 2016-17 & $29-29$ & $\mathrm{D}$ & $30-29$ & $\mathrm{~L}$ & 1 \\
\hline Lidl S.League & Nantes-Montpellier & 4 & 2017-18 & $26-28$ & $\mathrm{~V}$ & $27-30$ & $\mathrm{~V}$ & -1 \\
\hline Bundesliga & Kiel - Flensburg & 31 & $2015-16$ & $24-26$ & $\mathrm{~V}$ & $26-28$ & $\mathrm{~V}$ & 0 \\
\hline Bundesliga & Flensburg - Kiel & 19 & 2016-17 & $28-28$ & $\mathrm{D}$ & $30-29$ & $\mathrm{~L}$ & 1 \\
\hline Bundesliga & Magdeburg - Kiel & 22 & 2016-17 & $26-24$ & $\mathrm{~L}$ & $27-26$ & $\mathrm{~L}$ & -1 \\
\hline Bundesliga & Hannover - Kiel & 24 & 2016-17 & $24-26$ & $\mathrm{~V}$ & $26-27$ & $\mathrm{~V}$ & 1 \\
\hline Bundesliga & Berlin x Flensburg-H. & 26 & 2016-17 & $31-30$ & $\mathrm{~L}$ & $34-32$ & $\mathrm{~L}$ & 1 \\
\hline Bundesliga & Flensburg-Rehin Nekar & 31 & 2016-17 & $21-22$ & $\mathrm{~V}$ & $21-23$ & $\mathrm{~V}$ & -1 \\
\hline Bundesliga & Hannover-Burgdorf x Kiel & 24 & 2016-17 & $25-26$ & $\mathrm{~V}$ & $26-27$ & $\mathrm{~V}$ & 0 \\
\hline Bundesliga & Flensburg-H x Magdeburg & 3 & 2016-17 & $24-24$ & $\mathrm{D}$ & $26-25$ & $\mathrm{~L}$ & 1 \\
\hline Bundesliga & Kiel x Flensburg-H. & 11 & 2016-17 & $23-21$ & $\mathrm{~L}$ & $24-23$ & $\mathrm{~L}$ & -1 \\
\hline Bundesliga & $\begin{array}{l}\text { Magdeburgo x Flensburg- } \\
\text { H. }\end{array}$ & 24 & 2016-17 & $24-24$ & $\mathrm{D}$ & $24-24$ & $\mathrm{D}$ & 0 \\
\hline Bundesliga & Kiel x Hannover-Burgdorf & 1 & 2017-18 & $28-29$ & $\mathrm{~V}$ & $29-31$ & $\mathrm{~V}$ & -1 \\
\hline Bundesliga & Leizping $x$ Flensburg-H. & 4 & 2017-18 & $23-22$ & $\mathrm{~L}$ & $25-22$ & $\mathrm{~L}$ & 2 \\
\hline Bundesliga & Kiel - Leipzing & 5 & $2017-18$ & $29-25$ & $\mathrm{~L}$ & $29-26$ & $\mathrm{~L}$ & -1 \\
\hline Bundesliga & Gummersbach - R.Neckar & 5 & $2017-18$ & $24-29$ & $\mathrm{~V}$ & $26-29$ & $\mathrm{~V}$ & 2 \\
\hline
\end{tabular}

From left to right: championship, match, match day, season; goals 3 min before the end (Goal1) and result (Res1), goals at the end (Goal2) and result (Res2). Finally (Diff), margin of goals between home and visiting teams from Goal1. 


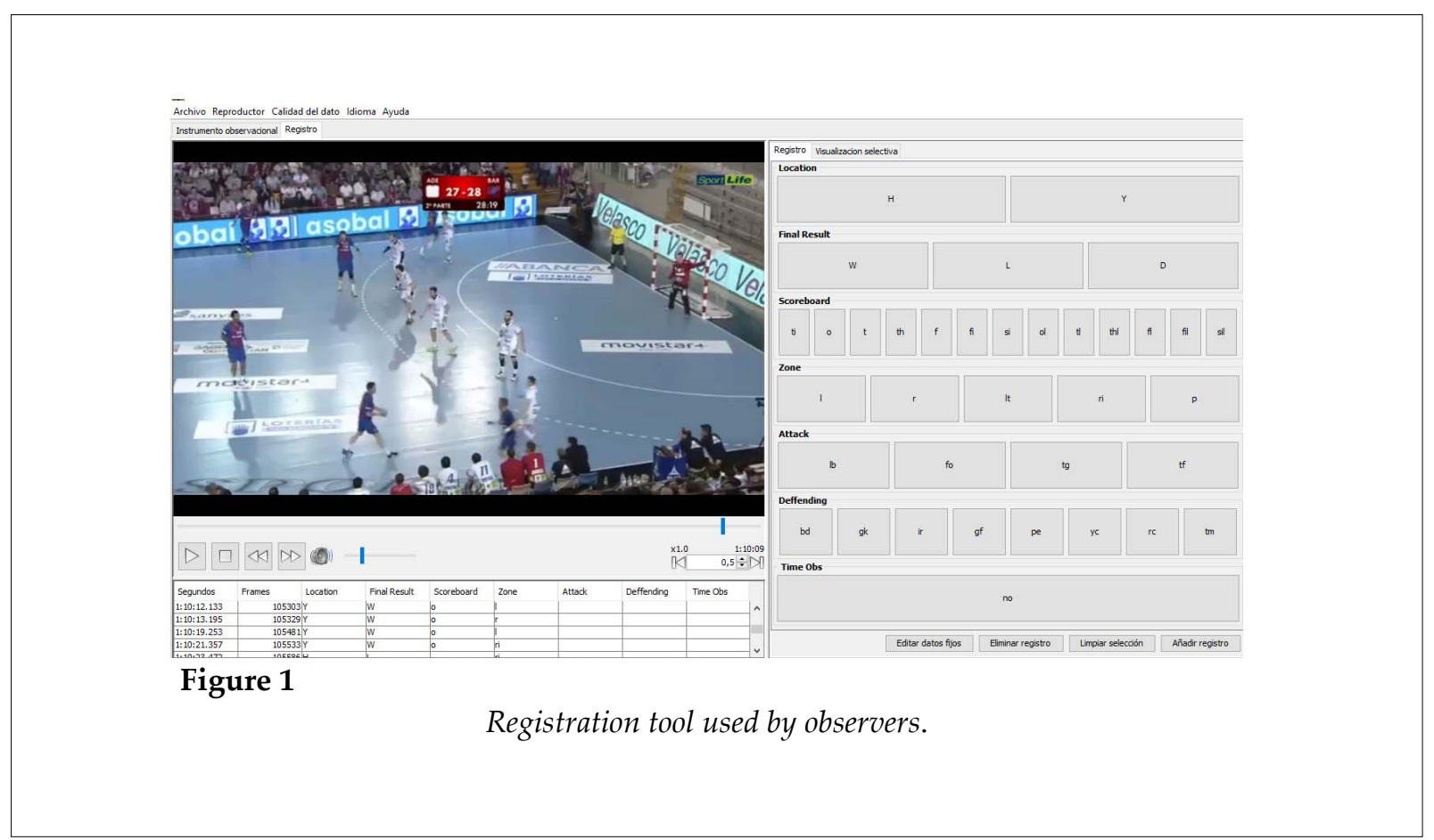

Table 2

Criteria, categories and codes in parentheses used to make the records.

\begin{tabular}{|c|c|}
\hline Criteria & Categories and coding \\
\hline 1. Location & a) home $(\mathrm{H}), \mathrm{b})$ away or visitors $(\mathrm{Y})$ \\
\hline 2. Final result & a) win $(W)$, lost $(L)$, draw (D). \\
\hline $\begin{array}{l}\text { 3.Scoreboard } \\
\text { evolution }\end{array}$ & $\begin{array}{l}\text { a) draw (ti), b) }+1(\mathrm{o}), \mathrm{c})+2(\mathrm{t}), \mathrm{d})+3(\text { th), e) }+4(\mathrm{f}), \mathrm{f})+5(\mathrm{fi}), \mathrm{g})+6(\mathrm{si}), \\
\text { h) }-1(\mathrm{ol}), \mathrm{i})-2(\mathrm{tl}), \mathrm{j})-3(\mathrm{thl}), \mathrm{k})-4(\mathrm{fl}), \mathrm{l})-5(\mathrm{fil}), 1 \mathrm{l})-6(\text { sil). }\end{array}$ \\
\hline 4. Zone & $\begin{array}{l}\text { a) left side of the team's attack since it crosses the midfield line } \\
\text { until it reaches the dashed line of } 9 \mathrm{~m}(\mathrm{l}) \text {. Same as above on the } \\
\text { right side (r). The left space between the penalty area and the } 9 \mathrm{~m} \\
\text { line (lt). Idem on the right side (ri). The throws from the penalty } \\
\text { point (p). }\end{array}$ \\
\hline
\end{tabular}

5. Attack a) loss of the ball (lb), b) attack foul (fo), c) goal (tg), missed shot (tf).

6. Deffending a) blocking of the rival throw, b) the goalkeeper stops or deflects the goal, c) intercepts or retrieves the ball (go), d) free-throw (gf), e) penalty (pe), f) yellow card (yc), g) red card (rc), h) expulsion 2 minutes (tm).

7. Time Obs a) Time out 
Table 3

T-Patterns by occurrences (PattOs) and different T-Patterns (PattDiff) found when performing specific searches $(t g, t f, o r, o l, t i, r i, l t)$ in home teams and visitors.

\begin{tabular}{ccccc} 
& \multicolumn{3}{c}{ Home } & \multicolumn{2}{c}{ Away } \\
\cline { 2 - 5 } & PattDiff & PattOccs & PattDiff & PattOccs \\
\hline tg & 267 & 826 & 97 & 291 \\
tf & 0 & 0 & 0 & 0 \\
o & 191 & 586 & 520 & 1767 \\
ol & 0 & 0 & 249 & 747 \\
ti & 766 & 2638 & 75 & 225 \\
ri & 466 & 1589 & 424 & 1365 \\
lt & 98 & 302 & 64 & 162 \\
\hline
\end{tabular}

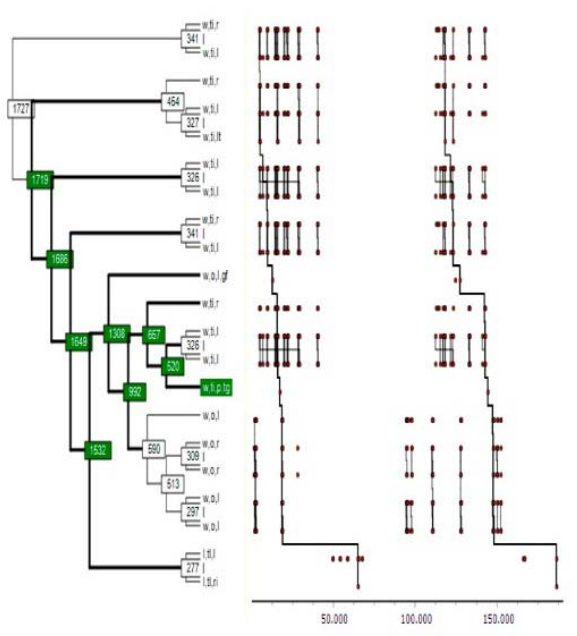

Figure 2a
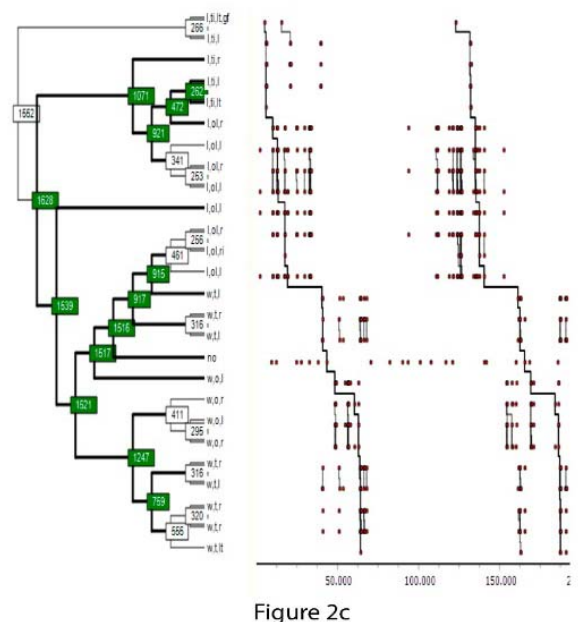
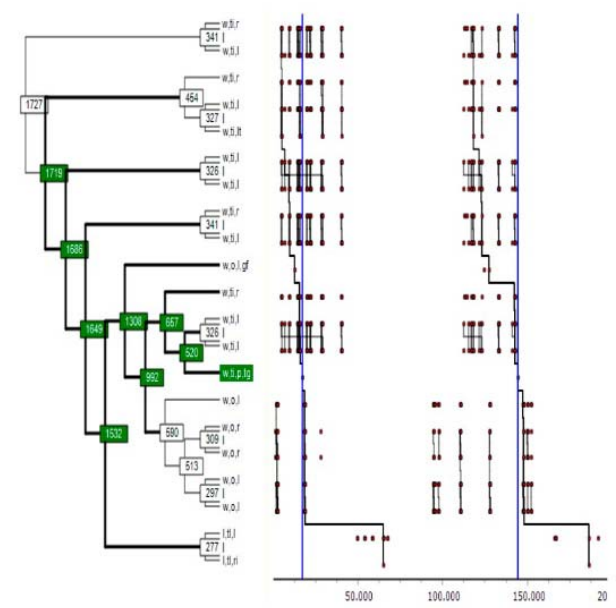

Figure $2 b$
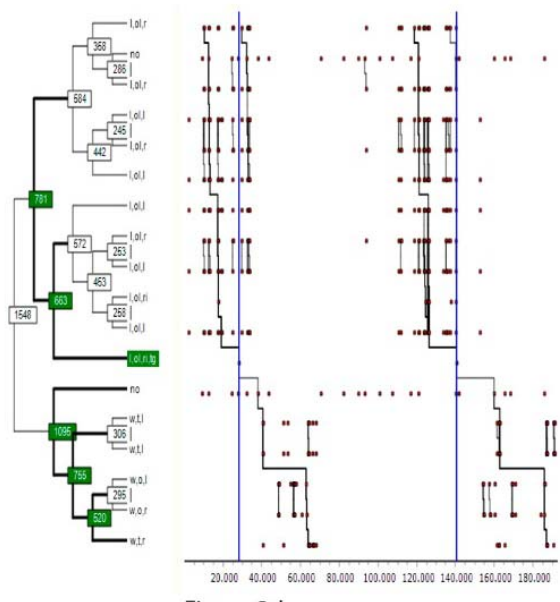

Figure $2 d$

Figure 2

Images generated by Theme v6. The upper images correspond to home teams and below, visiting teams.

On the upper left (Figure 2a) are the more complex T-Patterns, while on the left we searched for occurrences or events related to the goal (Figure 2b). In the two images below,

a generic search was also made to the left of T-Patterns (Figure 2c) while in the image on the right a search for the goal was specifically made (Figure 2d). 


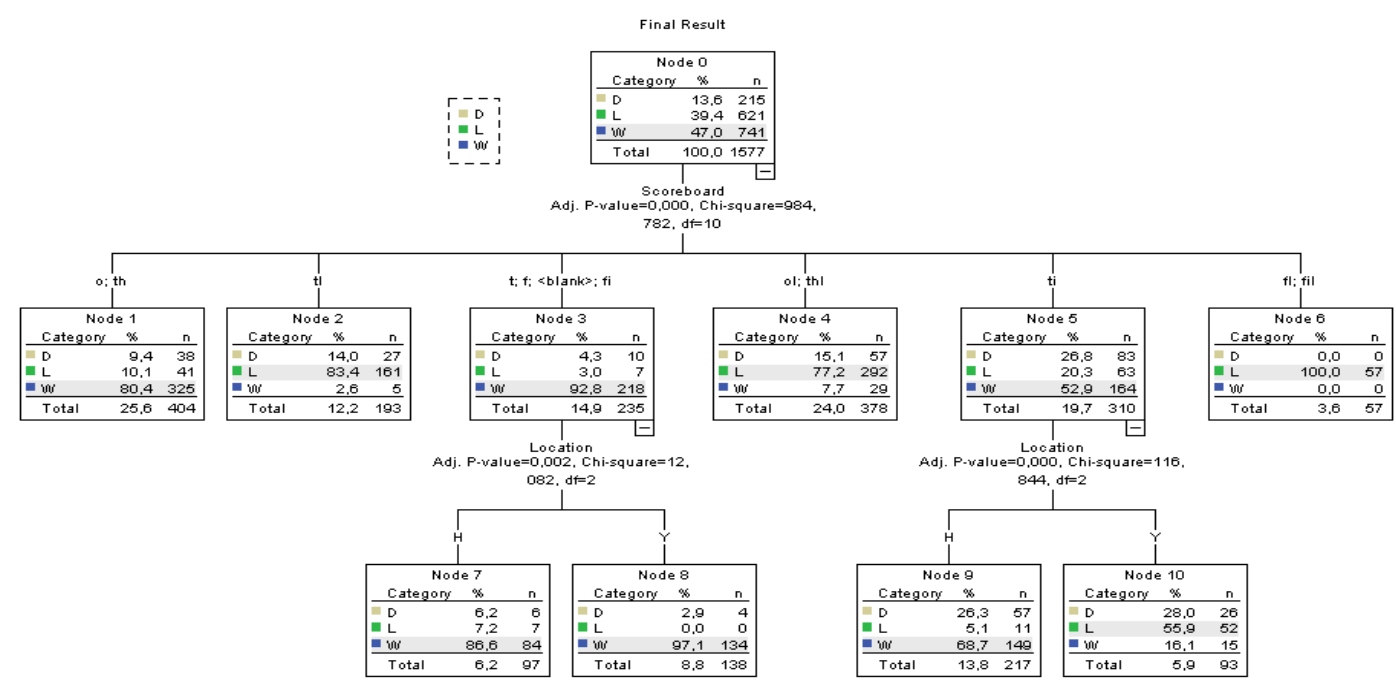

Figure 3

Variables of the predictive model (Chaid Model) included in the observational record system in Table 1.

\section{Discussion}

Investigating the phenomenon of $\mathrm{HA}$ in handball is very challenging (Agnew and Carron, 1994). The aim of this study was to find and analyze T-patterns (Borrie et al., 2002; Diana et al., 2017) in home and visiting handball teams through the use of an observational methodology (Anguera, 2017) along with the inquiry about more specific occurrences to better understand the HA concept.

Finding more T-patterns in home teams than in visitors when performing a search for occurrences (lt) (ri) could be part of the explanation of the T-patterns found in situations of scoring favorable goals in home teams. The reason for it was that throws with a greater chance of success would be those made in areas close to the rival goalkeeper (lt and ri). In this sense, the visiting teams could present a much more stereotyped performance in relation to the most decisive actions in handball, such as scoring goals (Flores et al., 2015). It was found that visitors got more $\mathrm{T}$-patterns and occurrences compared to home teams. However, the fact that getting a goal (tg) is such a decisive action, makes us consider that maybe home teams have a certain advantage identified by Theme expressed in temporal regularity, but hardly appreciable in an appearance look or when trying to reduce the data to frequencies exclusively. The most predictive occurrences in home teams $(\mathrm{w}, \mathrm{ti}, \mathrm{p}, \mathrm{tg})$ emerged without the need to perform a specific search for the occurrence goal (tg). Thus, the importance that this set of events had in home teams would be underlined. This did not happen to visiting teams, given that a set of events with predictive ability was not found, but a specific search of the goal $(\mathrm{tg})$ event was to be made in order to find (l, ol, ri, tg). Thus, this temporal order of occurrences observed in home teams, which included the goal (tg), justifies a difference against visiting teams, without forgetting that including the goal (tg) event in the search generated triple T-patterns in home teams compared to the rivals.

However, these differences were not contrasted by multivariate analysis (Chaid Model), given that the number of goals was not 
one of the most used occurrences in the registration system. At this point, and given the importance of the goal, chi-square analyses were performed and no significant values $(p>.05)$ were found between home teams and visitors. Guidelines provided by coaches to their players and the noise made by the spectators (Mayers et al., 2012; Nevill et al., 1999) to motivate their team, among others, may be grounds for better performances. However, the disadvantage of playing at home has also been noted (Wright and Voyer, 1995). Therefore, it has to be approached with a certain amount of caution as the HA phenomenon is multifactorial (Legaz-Arrese et al., 2013; Pollard and Pollard, 2005).

When starting with the registers, about 3 minutes before the end of the matches, the teams used to keep the advantage and, although the number of goals varied, the winning team used to end up winning, yet not in all cases. On twelve occasions this was not the case as there was a match where the home team lost the game despite having initially been in the lead, and in another occasion it happened the other way around. On two occasions, the visiting team was winning and finished the game tied, and on two other occasions the home team had an advantage and finished the game losing. The surprising fact is that in six matches the teams were tied three minutes before the end, but those matches were eventually won by home teams. On the other hand, the number of goals in favor of the home teams was 7, that is, subtracting the goals of advantage from the three minutes before the end to the goals at the end of the match to both teams separately.

Thus, by using Theme, a greater amplitude in the itineraries of home against visiting teams was detected, which could make home teams more apprehensive about confronting some rivals, since their actions would be more unpredictable. Also, the home teams obtained predictive T-patterns related to the realization of goals (Saveedra et al., 2017) that were not obtained by the visiting teams. On the other hand, multivariate analyses influenced the tie (ti) for the creation of new nodes, statistically significant between home and visitors. Although the difference in the number of goals between visitors and local teams was not significant, it equalled 5 goals when taking into account the advantages in goals before starting the records and at the end of matches. On the other hand, in situations of a draw $(n=6)$, home teams were winners at the end of the match.

Among the limitations of the study it should be mentioned that the difference in the score was restricted to a difference of no more than three goals between home teamss and visitors, thus the consideration of a priori quality indicators of each team could have enriched the present study. This recommendation could be useful to undertake new investigations including this and other variables such as the players' moods or guidelines provided by the coach (Staufenbiel et al., 2015) that could be decisive for how to compete at home. Having information about the most offensive or defensive line-ups in case of playing as a home or as a visitor team could result in a more predictable way of playing. Another possible line of research would be to make the records tracking performance of the same teams. In this study, given the difficulty of finding videos to analyze, the records were made without being able to compare the performances between the same teams (A against B, and later B against $A$ ). Future research could also focus not only on the circulation of the ball, but also on the action of the player without the ball. Finally, having more observers to ensure the quality of records is paramount in observational methodology, and perhaps a fundamental piece to achieve unquestionable reliability and validity standards.

The conclusion that can be drawn from this work, not without caution, would be the existence of the $\mathrm{HA}$ at critical moments in handball. The detection of temporary order in the attainment of decisive actions, which is favorable to the home team, would be of great importance. The HA also manifested itself in other circumstances: a) firstly, when the momentary scoreboard of the game indicated a draw, and b) secondly, when the teams were tied at the beginning of the registration and the game ended with a victory of the home team. These and other reasons make us reconsider the $\mathrm{HA}$, no longer due to the disagreement with its original concept, but with the aim of continuing advancing in new ways to identify the HA in high level competition handball matches. 


\section{References}

Anguera T. Introduction to Monograph on Observational Data Analysis. An Psycho, 2017; 33(3): 433-435

Anguera MT, Blanco-Villaseñor A, Hernández-Mendo A, Losada JL. Observational designs: their suitability and application in sports psychology. Cuad Psicol Deporte, 2011; 11: 63-76.

Anguera MT. Observational typology. Qual Quant, 1979; 13: 449-484

Amatria M, Lapresa D, Arana J, Anguera MT, Garzón B. Optimization of Game Formats in U10 Soccer Ussing Logistic Regression Analysis. J Hum Kinet, 2016; 54: 163-171

Amatria M, Lapresa D, Arana J, Anguera MT, Jonsson GK. Detection and Selection of Behavioral Patterns Using Theme: A Concrete Example in Grassroots Soccer. Sports, 2017; 5(1): 20

Agnew GA, Carron AV. Crowd effects and the home advantage. Int J Sport Psychol, 1994; 25: 53-62

Borrie A, Jonsson GK, Magnusson MS. Temporal pattern analysis and its applicability in sport: An explanation and exemplar data. J Sport Sci, 2002; 20(10): 845-852

Courneya KS, Carron AV. The home advantage in sport competitions: A literature review. J Sport Exercise Psy, 1992; 14: 13-27

Diana B, Zurloni V, Elia M, Cavalera CM, Jonsson GK, Anguera MT. How Game Location Affects Soccer Performance: T-Pattern Analysis of Attack Actions in Home and Away Matches. Front Psychol, 2017; 8: 1415

Flores R, Forrest D, Pablo C, Tena JD. What is a good result in the first leg of a two-legged football match?. Eur J Oper Res, 2015; 247(2): 641-647

Gabín B, Camerino O, Anguera MT, Castañer M. Lince: multiplatform sport analysis software. Proc Soc Behav Sci, 2012; 46: 4692-4694

Gómez MA, Pollard R, Luis-Pascual JC. Comparison of the home advantage in nine different professional team sports in Spain. Percept Motor Skill, 2011; 113: 150-156

Gutiérrez O, Saavedra M, Fernández JJ. Determining home advantage in Spanish handball. Percept Motor Skills, 2012; 114(1): 329-338

Gutiérrez Ó, Saavedra M, Fernández JJ. Effect of Being the Organizer of a Handball World Championship in Team Performance. Rev Int Med Cienc Ac, 2015; 15(57): 139-150

Jamieson JP. Home field advantage in athletics: a metaanalysis. J Appl Soc Psychol, 2010; 40: 1819-1848

Julio UF, Panissa VL, Miarka B, Takito MY, Franchini E. Home advantage in judo: A study of the world ranking list. J Sports Sci, 2013; 31(2): 212-218

Koning RH. Home advantage in professional tennis. J Sports Sci, 2011; 29(1): 19-27

Krumer A. On winning probabilities, weight categories, and home advantage in professional judo. J Sports Econ, 2017; 18(1): 77-96

Lago-Peñas C, Fernández-Villarino MA, González-García I, Sánchez-Fernández P, Sampaio J. The impact of a good season start on team performance in elite handball. J Hum Kinet, 2016; 50: 195-202

Legaz-Arrese A, Moliner-Urdiales D, Munguía-Izquierdo D. Home advantage and sports performance: evidence, causes and psychological implications. Univ Psychol, 2013; 12(3): 933-943

Lozano D, Camerino O. Effectiveness of Offensive Systems in Handball. Apunts. Educación Física y Deportes, 2012; 108: 66-77

Magnusson MS. Discovering hidden time patterns in behavior: T-patterns and their detection. Behav Res Method Ins Comput, 2000; 32: 93-110

Montoya M, Moras G. Anguera MT. Analysing Completions by Wing Players in Handball. Apunts. Educación Física y Deportes, 2013; 113: 52-59

Myers TD, Nevill AM, Al-Nakeeb Y. The influence of crowd noise upon judging decisions in Muay Thai. Adv Phys Educ, 2012; 2: 148-152

Nevill AM, Balmer NJ, Williams AM. Crowd influence on decisions in association football. Lancet, 1999; 353: 1416

Pollard R. Home advantage in soccer: A retrospective analysis. J Sport Sci, 1986; 4(3): 237-248

Pollard R, Pollard G. Home advantage in soccer: a review of its existence and causes. Int J Soccer Sci, 2005; 3(1): 28-38 
Pollard R. Home Advantage in Football: A current review of an unsolved puzzle. Open Sports Sci J, 2008; 1(1): 12-14

Pollard R, Prieto J, Gómez MA. Global differences in home advantage by country, sport and sex. Int J Perform Anal Sport, 2017; 17(4): 586-599

Saavedra JM, Porgeirsson S, Krisjansdottir H, Chang M, Halldorsson K. Handball game-related statistics in men at Olympic Games (2004-2016): Differences and discriminatory power. Retos, 2017; 32: 260-263

Staufenbiel K, Lobinger B, Strauss B. Home advantage in soccer-a matter of expectations, goal setting and tactical decisions of coaches? J Sport Sci, 2015; 33(18): 1932-1941

Strauss B, Bierschwale J. Spectators and the home advantage in the German national handball league. Zeitschrift fur sportpsychologie, 2008; 15(3): 96-101

Wright EF, Jackson W. The home-course disadvantage in golf championships: Further evidence for the undermining effect of supportive audiences on performance under pressure. J Sport Behav, 1991; 14: 5160

Wright EF, Voyer D. Supporting audiences and performance under pressure: The home-ice disadvantage in hockey championships. J Sport Behav, 1995; 18: 21-28

\section{Corresponding author:}

\section{Miguel Pic}

University of La Laguna, Department of Specific Didactics.

Heraclio Sánchez, 43, 38204 La Laguna, Tenerife (Spain)

Phone: 922 319665/9650

Fax: 922319683

E-mail: pic.aguilar.90@ull.edu.es 